\title{
Smart Approach for Preparing Nanosized Topiramate Loaded Bio- Flexy Films Using Film Former from Piper Nigrum and Screening its In- Vitro Performance
}

\section{Varshney S* and Satheesh Madhav NV \\ Faculty of Pharmacy, DIT University, India}

*Corresponding author: Sugandha Varshney, Faculty of Pharmacy, DIT University,

\section{Research Article}

Volume 3 Issue 3

Received Date: July 26, 2018

Published Date: August 30, 2018

DOI: $10.23880 /$ nnoa-16000147

Dehradun, 248001, India, Tel: 08439468596; Email: sugandhavarshney19.12.86@gmail.com

\section{Abstract}

Purpose: To formulate nanosized bio-flexy films using a novel biopolymer isolated from Piper nigrum seeds containing Topiramate for epilepsy treatment. Soft palate drug delivery bypasses first-pass metabolism in gastrointestinal tract. Piper nigrum biopolymer possessed biodegradability, biocompatibility, non-toxicity, inertness, non-reactiveness on soft palatal surface, cost effectivity. Topiramate, anticonvulsant drug, augments the activity of neurotransmitter gammaamino butyrate (GABA). Thus, to minimize drug dose, frequency and side effects like suicidal thoughts and sudden unexpected death, this attempt of Bio-flexy films formulations was made.

Methods: Bio-flexy films were prepared by solvent casting technique. Varying ratios of topiramate: Piper nigrum biopolymer were chosen for preparing formulations (FNO1-FNO5) and compared with Sodium carboxyl methyl cellulose standard films and evaluated.

Results: The percentage yield of Piper nigrum biopolymer was found to be $2.2 \% \pm 0.02$. Shear Stress study of Piper nigrum biopolymer showed promising mucoadhesivity than standard Sodium Carboxyl Methyl standard polymer. Thickness of formulations (FNO1-FN05): $0.029 \pm 0.003 \mathrm{~mm}$ to $0.039 \pm 0.002 \mathrm{~mm}$, Folding Endurance: $91-124$, Surface pH: $7.02 \pm 0.02$ to $7.02 \pm 0.01$, Weight Uniformity: $0.016 \pm 0.08$ to $0.030 \pm 0.07$, Drug Content Uniformity: $89.7 \% \pm 0.72$ to 95.4\% \pm 0.54 , Swelling Percentage: $66 \% \pm 0.5$ to $72 \% \pm 0.4$, Tensile Strength: 88.54 gm \pm 2.5 to 102.05 gm \pm 2.4 , Percentage Moisture Uptake (PTU): $2.2 \% \pm 0.13$ to $2.4 \% \pm 0.12$, more mucoretentive on Capra aegagrus intestinal mucosa than standard Sodium Carboxyl Methyl Cellulose films.

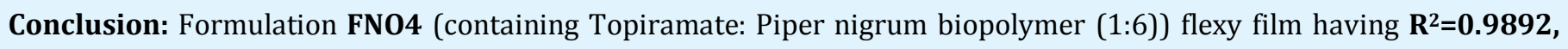
Peppas Korsemeyer as best fit model, follows Fick an Diffusion (Higuchi Matrix) release mechanism, T50\%: 6 hrs, T80\%: 28 hrs, was selected as Best bio-flexy film.

Keywords: Bio-flexy films; Nanosized Topiramate; Soft palatal delivery; Piper nigrum biopolymer 


\section{Nanomedicine \& Nanotechnology Open Access}

Abbreviations: Sodium CMC: Sodium Carboxyl Methyl Cellulose; FNO: Bio Flexy Film Formulation of Topiramate with Piper nigrum biopolymer; FSO: Bio Flexy Film Formulation of Topiramate with Sodium CMC standard polymer; GIT: Gastro Intestinal Tract; no.: Number; U.V: Ultraviolet Visible Spectroscopy; I.R: Infra-Red Spectroscopy; SEM: Scanning Electron Microscopy; DSC: Differential Scanning Calorimetry; NMR: Nuclear Magnetic Resonance; $\mathrm{cm}^{2}$ : Centimeters Square; mins.: Minutes; mm: Millimeters; hrs: Hours; mL: Milliliters; gm: Grams; Mg: Milligram; rpm: Revolutions per minute; KBr: Potassium Bromide; Std: Standard.

\section{Introduction}

Soft Palate (velum) is a part of Oral mucosa, suspended from the posterior border of the hard palate, protects nasal passage, no bone, non-keratinized histology, more convenient means of drug administration, systemic absorption than oral administration to Gastro Intestinal Tract [1]. Surface area of the oral mucosa (200 $\mathrm{cm}^{2}$ ) relatively small compared with the Gastro Intestinal Tract $\left(350,000 \mathrm{~cm}^{2}\right.$ and skin $\left(20,000 \mathrm{~cm}^{2}\right)$.

Targeting of drugs to brain is difficult to achieve due to Blood Brain Barrier. Trans-Soft Palatal route offers a novel, unique Drug Delivery Platform for systemic drug delivery for Brain targeting [2]. It is for retentive drug delivery and is acceptable to patients. With the right dosage form design and formulation, the permeability and the local environment of the mucosa can be controlled and manipulated in order to accommodate drug permeation. Palatal drug delivery is a promising area for systemic delivery of orally inefficient drugs, potent peptide and protein drug molecules. Blood supply to Soft palate is by Middle Meningeal artery; Accessory Meningeal artery; Greater Palatine branch of maxillary artery; ascending palatine branch of facial artery; ascending pharyngeal artery [2]. Soft palate is innervated by mandibular branch of trigeminal nerve (Cranial nerve V); Lesser palatine nerve; greater palatine nerve; nasopalatine nerve; glossopharyngeal nerve; motor nerves. When nano sized drug is administered by this route, then via inter and intra neural pathway, it can directly reach into brain by trigeminal nerve that directly connects soft palate to brain [3].

Epilepsy ranks $7^{\text {th }}$ position causing $3.3 \%$ total deaths worldwide, that is expected to rise up to 6th position causing $3.7 \%$ of total deaths till year 2030. Antiepileptic drug Topiramate available as tablets dosage forms only which shows delayed action due to First Pass Metabolism in Gastro Intestinal Tract. In this research work, an inert, biodegradable cost effective biopolymer obtained from Piper nigrum pulp was incorporated to avoid toxicity that is by synthetic polymers. Piper nigrum contains 3\% essential oil, sabinene, beta-pinene, limonene, terpinene, alpha-pinene, myrcene, delta3-carene and monoterpene derivatives (borneol, carvone, 1,8-cineol, linalool) [4]. Drugs directly enter the systemic circulation [5]. This route is non-invasive, non-mobile with highly mucoretention ability, afford high bioavailability, drugs directly enter the systemic circulation, lower doses, avoidance of the first-pass metabolism by the liver and metabolism by gastrointestinal tract. Topiramate, anticonvulsant drug possesses $\mathrm{t} 1 / 2: 19-30$ hours; protein binding: $13-17 \%$; water solubility: $9.8 \mathrm{mg} / \mathrm{L}$. It reduces glutamatergic neurotransmission. Adverse effects are abdominal pain, pharyngitis, suicidal thoughts and sudden unexpected death. Thus to decrease dose frequency and to minimize adverse drug reactions, nanosized Topiramate loaded Bio-flexy films were suitably formulated that can provide sustained drug action up to 48 hours.

Importance and advantages of using biopolymer instead of using synthetic polymers like carboxyl methyl cellulose and hydroxyl propyl methyl cellulose.

1. Isolated biopolymer exhibited significant biodegradability, mucoadhesivity, filmability, retardabi lity and comparable to synthetic polymers.

2. Economically cheap and environment friendly.

3. Suitable as a drug carrier for sustained release dosage forms with suitable modification.

4. It can applicable in Pharmaceutical Industries and commercialized effectively.

5. Piper nigrum biopolymer is having uniqueness of being pure, natural origin isolated from Black pepper seeds.

6. Hydroxyl Propyl Methyl Cellulose, Carboxyl Methyl Cellulose are synthesized using various harmful chemicals. Thus, biopolymer avoids toxicity that is by synthetic polymers.

7. Biopolymer serves as a suitable drug carrier for the formulation of bio-flexy films.

\section{Materials and Methods}

DRUG-Topiramate (procured from Sun Pharmaceuticals Industries Ltd., Gujarat) POLYMERSPiper nigrum biopolymer (Black pepper seedsprocured from local market) Sodium Carboxyl Methyl Cellulose 


\section{Nanomedicine \& Nanotechnology Open Access}

(Central drug House (P) Ltd. New Delhi) All other reagents used were of highest purity and analytical grade. Double distilled water was used throughout the experimental work.

\section{Isolation of Biomaterial from Piper nigrum}

50 gm Black Pepper was stirred with $85 \mathrm{ml}$ Methanol + $10 \mathrm{ml}$ Glacial Acetic Acid $+5 \mathrm{ml}$ Conc. Sulphuric Acid to the residue added $10 \mathrm{ml}$ of Sodium Hydroxide solution. Magnetic Stirring was done for 30 mins, Residue was filtered. Added $50 \mathrm{ml}$ of Methanol. Added Calcium Hydroxide (Slaked Lime) until pH 9 was obtained. Mixed, Filtered after 30 mins, Filtrate was concentrated. Added to $25 \mathrm{ml}$ cold water for 5-10 mins, centrifuged. To the supernatant, $50 \mathrm{ml}$ acetone was added and kept for refrigeration. To the precipitate obtained by centrifugation, added Water: Chloroform (1:2) Kept for 2 hrs of Magnetic Stirring, air dried to obtain biopolymer. Isolated biopolymer was powdered, passed through Sieve No. 120, packed and stored. Optimized six times, reported $\%$ yield.

\section{Physicochemical Characterization}

Physicochemical properties of isolated bio-material were characterized.

Physical Parameters: Color, Odor, Texture and Color Changing Point. Color, Odor, Texture of Bio-polymer was examined physically. Color Changing Point was determined by Capillary method by Melting Point Apparatus. Firstly the bio-polymer was kept in a Capillary tube and it was fitted in a Melting Point Apparatus. Temperature at which bio-polymer melts and changes its color was determined by means of a Thermometer and reported.

Chemical Parameters: Tests for Carbohydrates, Proteins, Starch and Reducing Sugar.

\section{a) Test for carbohydrates}

Molisch reagent test $2 \mathrm{~mL}$ of biopolymer solution $(0.1 \mathrm{gm}$ dissolved in $2 \mathrm{~mL}$ of distilled water) was taken in a test tube. 2 drops of Molisch reagent (Solution of $\alpha$-napthol in $95 \%$ ethanol) was added. Solution was then poured slowly into a test tube containing $2 \mathrm{~mL}$ of concentrated sulfuric acid. Two layers were formed. Purple color appeared at interface of the two layers due to formation of 5-hydroxy methyl furfural.

\section{b) Test for proteins}

Biuret test determines the presence of peptide bonds in protein content in the isolated biomaterial. $2 \mathrm{~mL}$ of biomaterial solution ( $0.1 \mathrm{gm}$. dissolved in $2 \mathrm{~mL}$ of distilled water) was taken in a test tube. $1 \mathrm{~mL}$ of sodium hydroxide solution (1\%) followed by $1 \%$ copper (II) sulphate solution was added drop wise. Test tube was then shaken vigorously. Allowed the mixture to stand for 5 minutes and observed the color change. Biuret test is based on the ability of $\mathrm{Cu}$ (II) ions to form a violetcolored chelate complex with the peptide bond (CONH groups) in alkaline conditions. The chelate complex absorb light at $\mathbf{5 4 0} \mathbf{~ n m s o ~ i t ~ a p p e a r e d ~ v i o l e t . ~}$ Color change indicated presence of proteins.

c) Test for Starch $2 \mathrm{~mL}$ of biomaterial solution $(0.1 \mathrm{gm}$. dissolved in $2 \mathrm{~mL}$ of distilled water) was taken in a test tube. 1-2 drops of iodine solution was added. Then observed the color change. Appearance of an intense blue black color confirmed the presence of starch in isolated biomaterial (transfer of charge between starch and iodide ion changes the spacing between the energy orbitals, so starch-iodide complex absorb light at higher wavelength)

d) Test for Reducing Sugar $2 \mathrm{~mL}$ of biopolymer solution ( $0.1 \mathrm{gm}$. dissolved in $2 \mathrm{~mL}$ of distilled water) was taken in a test tube. Added $1 \mathrm{~mL}$ each of Fehling's A $(7 \mathrm{~g}$ $\mathrm{CuSO}_{4} .5 \mathrm{H}_{2} \mathrm{O}$ dissolved in distilled water containing 2 drops of dilute sulfuric acid) and Fehling's B (35 gm. potassium tartrate, $12 \mathrm{gm}$. of sodium hydroxide in $100 \mathrm{~mL}$ of distilled water). The test tube was placed in a waterbath at $60^{\circ} \mathrm{C}$. Appearance of brick red precipitate of insoluble copper oxide indicated the presence of reducing sugar in isolated biomaterial.

\section{Drug-Excipient Interaction Study}

Drug-excipient interaction study was performed by taking three different ratios of drug and bio-material 1:1, 1:3 and 3:1 [5]. The Ultraviolet (U.V.) absorbance of the three ratios was taken and compared with the absorbance of pure drug.

\section{a) Wet method}

Drug-excipient in the ratio of $1: 1,1: 3$ and $3: 1$ were taken in 3 different petridishes. $1 \mathrm{~mL}$ of distilled water was added to wet the mixtures. Mixtures were then subjected to drying in oven for $30 \mathrm{mins}$ at $50^{\circ} \mathrm{C}$, followed by dilution with $2 \mathrm{~mL}$ of methanol. Ultraviolet Spectroscopy study was performed. The shift in $\lambda_{\max }$ was reported in comparison to that of pure Topiramate.

\section{b) Dry method}

Drug-excipient in the ratio of $1: 1,1: 3$ and $3: 1$ were taken in their physical forms (dry) in 3 different

\footnotetext{
Varshney S and Satheesh Madhav NV. Smart Approach for Preparing Nanosized Topiramate Loaded Bio-Flexy Films Using Film Former from Piper Nigrum and Screening its In-Vitro Performance. Nanomed Nanotechnol 2018, 3(3): 000147.
}

Copyright(C) Varshney S and Satheesh Madhav NV. 


\section{Nanomedicine \& Nanotechnology Open Access}

petridishes. Mixtures were kept at room temperature for $2 \mathrm{hrs}$, followed by dilution with $2 \mathrm{~mL}$ of methanol. Ultraviolet spectroscopy study was then performed. The shift in $\lambda_{\max }$ was reported in comparison to that of pure Topiramate.

c) Colorimetry Method: Drug: Polymer 1:1 were mixed with Potassium Permanganate on glass plate. Observed color change, scrapped, Diluted suitably with distilled water, analyzed by UV. Similarly repeated with Drug: Distilled Water and Drug: Potassium Permanganate.

\section{Importance of determination of drug-biopolymer interaction by Dry and Wet methods}

The two methods revealed that no interaction of drugbiopolymer occurred either in dry form on in presence of solvent. Since biopolymer is isolated from natural source and used in formulation, it has to be ascertained whether the biopolymer is inert in both dry (during storage) as well as wet (if used in oral drug delivery) conditions. Thus to confirm inertness and non-reactiveness of biopolymer with drug, these two methods had been performed. The drug was found to be intact with biopolymer

\section{Spectral studies of isolated biopolymer}

SEM Analysis: Morphological examination of the surface and internal structure of the biomaterial was performed by using a scanning electron microscope (SEM). A small amount of biomaterial was fixed on aluminum studs and it was coated with gold using a sputter coater under vacuum (pressure: $1 \mathrm{~mm} \mathrm{Hg}$ ). The biomaterial was then analyzed by SEM $[5,6]$.

FTIR Spectra: The physical form of isolated bio-material was solid. $\mathrm{KBr}$ disc method was employed for IR spectroscopy, and in this technique about $1 \mathrm{mg}$ of the solid sample was mixed with about $100 \mathrm{mg}$ of pre dried and desiccated solid $\mathrm{KBr}$. The mixture was finely ground in a mortar, preferably under an IR lamp to exclude any water vapors. The finely ground mixture was pressed under pressure of about 10 tons using a hydraulic pump to form a small pellet about $1-2 \mathrm{~mm}$ in diameter. The resulting $\mathrm{KBr}$ disc was removed from the $\mathrm{KBr}$ die and is positioned in a special holder into the path of the IR radiation and its spectrum was recorded within the range of $4000-200 \mathrm{~cm}^{-1}$.

Differential Scanning Calorimetry: (DSC) is a thermoanalytical technique in which the difference in the amount of the heat required to increase the temperature of a sample and reference is measured as a function of temperature. It was performed for determination of Glass Transition temperature (GTT or Tg). For DSC the Perkin
Elmer Instrument, Model- JADE DSC will be used, with the Heat flow of $50-250^{\circ} \mathrm{C}$ at the rate of $10^{\circ} \mathrm{C} /$ minute and Nitrogen flow rate of $20 \mathrm{ml} / \mathrm{minute}$ will be used.

NMR Spectral Analysis: Nuclear magnetic resonance (NMR) is a physical phenomenon in which magnetic nuclei in a magnetic field absorb and re-emit electromagnetic radiation. This energy is at a specific resonance frequency which depends on the strength of the magnetic field and the magnetic properties of the isotope of the atoms. Solvent used is DMSO (Dimethyl Sulfoxide). The spectrometer is connected to the process with a $5 \mathrm{~mm}$ diameter flow cell. The reaction mixture is pumped with high flow rates to the instrument, a valve switch to stop the flow is activated so the instrument can perform a quick measurement. Afterwards, the valve switches back and the flow cell in the instrument is rinsed again with the reaction mixture. After a measurement is finished, the spectrum is sent to the automation computer where it can be processed and analyzed.

Preparation of standard curve of Topiramate: $10 \mathrm{mg}$ of Topiramate was dissolved in $30 \mathrm{~mL}$ of Phosphate Buffer (pH 7.4) in a $100 \mathrm{~mL}$ volumetric flask and diluted up to the mark with Buffer (pH 7.4) $(100 \mu \mathrm{g} / \mathrm{mL})$. Dilutions of Concentrations $(0.5,1,2,3,4$ and $5 \mu \mathrm{g} / \mathrm{mL})$ were prepared in $10 \mathrm{~mL}$ volumetric flasks. Volume was made up to $10 \mathrm{~mL}$ with Phosphate Buffer $\left(\lambda_{\max }=244 \mathrm{~nm}\right)$. Absorbance was measured against solvent blankc $[7,8]$.

\section{Nanosizing of Topiramate}

Nanosizing of Topiramate by Standard Solvent Evaporation Method: $100 \mathrm{mg}$ Topiramate was mixed with $10 \mathrm{mg}$ dextrose, $5 \mathrm{mg}$ fructose and $10 \mathrm{~mL}$ methanol in mortar pestle and triturated. The mixture was transferred into beaker, sonicated for 5 cycles (3mins/cycle in ultrasonic bath sonicator). Mixture was diluted with $50 \mathrm{~mL}$ distilled water and again sonicated for 5 cycles. Absorbance, \% Transmittance, \% Blockage (100\% Transmittance) was noted after every 5 cycles up to 15 cycles. After $15^{\text {th }}$ cycle, residue was collected, dried, packed and stored.

Nanosizing of Topiramate by Sonication method: 100 mg Topiramate was mixed with $10 \mathrm{mg}$ dextrose, $5 \mathrm{mg}$ fructose and $10 \mathrm{~mL}$ distilled water in mortar pestle and triturated. The mixture was transferred into beaker, sonicated for 5 cycles (3mins/cycle in ultrasonic bath sonicator). Mixture was diluted with $50 \mathrm{~mL}$ distilled water and again sonicated for 5 cycles. Absorbance, \% Transmittance, \% Blockage (100- \%Transmittance) was 


\section{Nanomedicine \& Nanotechnology Open Access}

noted after every 5 cycles up to 15 cycles. After $15^{\text {th }}$ cycle, residue was collected, dried, packed and stored.
The main purpose of Nanosizing Topiramate by two different methods was to compare novel sonication method with published standard solvent evaporation method (Figure 1).

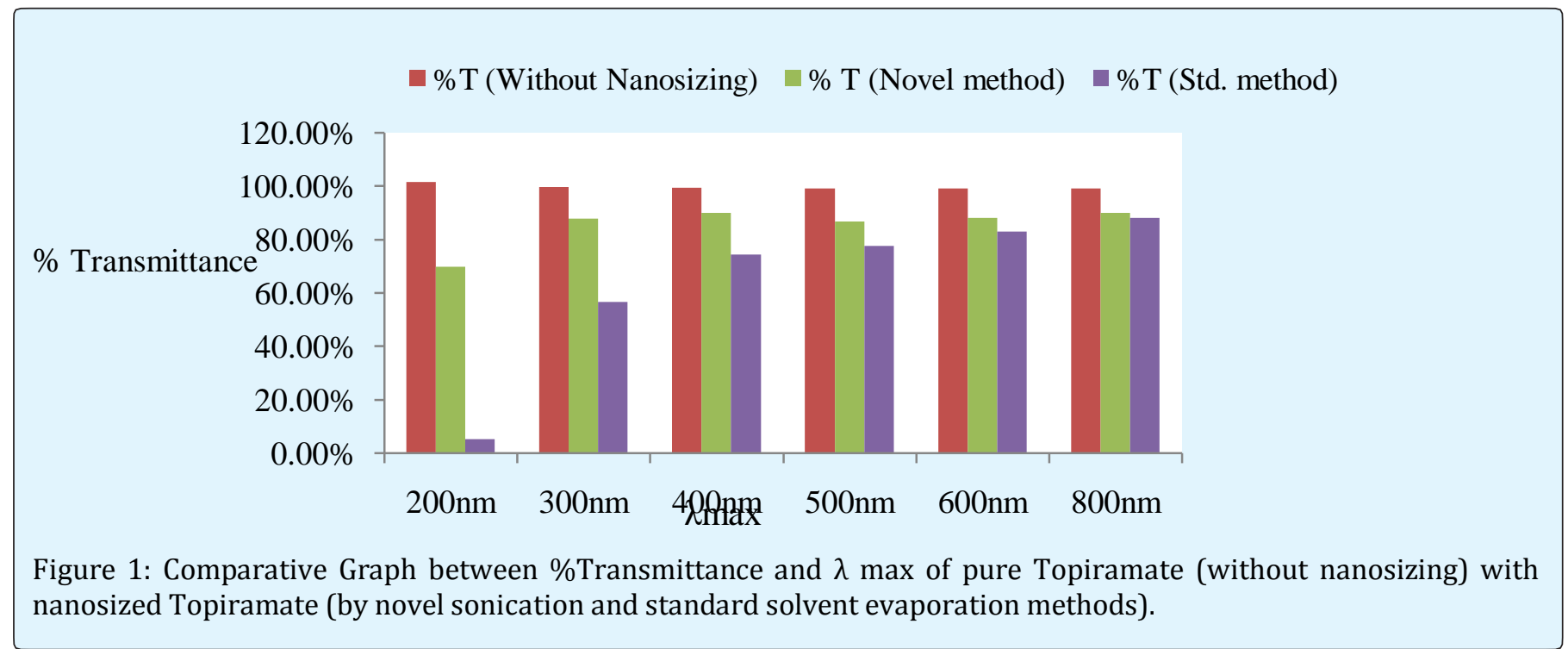

\section{Formulation of Bio-flexy Films (Solvent Casting Method)}

Nanosized Topiramate (anticonvulsant) and Piper nigrum biopolymer (in ratios 1:1, 1:3, 1:5, 1:6, 1:10) (retardant, mucoadhesive agent, film former) were taken in mortar. To this mixture, dextrose $(10 \mathrm{mg} / \mathrm{mL})$, fructose $(5 \mathrm{mg} / \mathrm{mL})$ (flexicizers) were added and triturated. Added glycerine $(10 \mu \mathrm{l})$ (plasticizer), pectin (3\%) (Film initiator). Distilled water $(20 \mathrm{~mL})$ was incorporated, uniformly triturated for 2 mins. Mixtures were subjected to magnetic stirring for 15 mins, followed by sonication for up to 5 cycles (each cycle 3 minutes). Nano-dispersions were poured into petridishes and kept for drying. Prepared films were removed from petridishes by using $1 \%$ borax solution (hardening agent) Checked the filmability of prepared films. Same procedure was followed for formulations of Standard Polymer Films (Tables 1 \& 2).

\begin{tabular}{|c|c|c|c|c|c|}
\hline Formulation & FNO1 & FNO2 & FNO3 & FNO4 & $\begin{array}{c}\text { FNO5 } \\
(\mathbf{1 : 1 0})\end{array}$ \\
\hline Topiramate (mg) & 100 & 100 & 100 & 100 & 100 \\
\hline Piper nigrum (mg) & 100 & 300 & 500 & 600 & 1000 \\
\hline Dextrose (mg) & 100 & 100 & 100 & 100 & 100 \\
\hline Fructose (mg) & 50 & 50 & 50 & 50 & 50 \\
\hline Glycerine (pl) & 10 & 10 & 10 & 10 & 10 \\
\hline Pectin (gm.) & 0.6 & 0.6 & 0.6 & 0.6 & 0.6 \\
\hline Distilled Water (mL) & 10 & 10 & 10 & 10 & 10 \\
\hline
\end{tabular}

Table 1: Formulation of Bio-flexy films using (Piper nigrum) biopolymer. 


\section{Nanomedicine \& Nanotechnology Open Access}

\begin{tabular}{|c|c|c|c|c|c|}
\hline Formulation & FSO1 (1:1) & FSO2 (1:3) & FSO3 (1:5) & FSO4 (1:6) & FSO5 (1:10) \\
\hline Topiramate (mg) & 100 & 100 & 100 & 100 & 100 \\
\hline Sodium Carboxyl Methyl Cellulose (mg) & 100 & 300 & 500 & 600 & 1000 \\
\hline Dextrose (mg) & 100 & 100 & 100 & 100 & 100 \\
\hline Fructose (mg) & 50 & 50 & 50 & 50 & 50 \\
\hline Glycerine ( $\mu \mathbf{l})$ & 10 & 10 & 10 & 10 & 10 \\
\hline Pectin (gm.) & 0.6 & 0.6 & 0.6 & 0.6 & 0.6 \\
\hline Distilled Water (mL) & 10 & 10 & 10 & 10 & 10 \\
\hline
\end{tabular}

Table 2: Formulation of Bio-flexy film using Sodium Carboxyl Methyl Cellulose Standard polymer.

\section{Evaluation of Formulated Bio-Flexy Films}

Thickness: The thickness of randomly selected bio-flexy films from every batch was determined using standard digital micrometer. The average thickness was determined and reported with appropriate standard deviation [8].

Folding Endurance: Folding endurance of bio-flexy films was determined by repeatedly folding one of the film at the same place till it broke or folded up to 300 times manually, which was considered satisfactory to reveal good properties. The number of times of film could be folded at the same place without breaking gave the value of the folding endurance. This test was done on randomly selected three flexy films from each batch.

Surface pH Study: The surface pH of bio-flexy films was determined in order to investigate the possibility of any side effects in vivo. As an acidic or alkaline $\mathrm{pH}$ may causes irritation to the soft palatal mucosa, it was determined to keep the surface $\mathrm{pH}$ as close to neutral as possible. The bio-flexy films were allowed to swell by keeping it in contact with $1 \mathrm{ml}$ of distilled water for 1 hour at room temperature. The $\mathrm{pH}$ was measured by bringing the electrode in contact with the surface of film and allowing it to equilibrate for 1 minute. The experiments were performed in triplicate and avg. values were reported. Surface $\mathrm{pH}$ of films was determined because prepared bio-flexy films will be directly placed in soft palatal region, thus it is essential for formulation (rather than polymeric solution) to be neutral to mucosal surface and compatible with soft palatal $\mathrm{pH}$.

Weight Uniformity Study: determined by taking weight of ten bio-flexy films of sizes $1 \mathrm{~cm}^{2}$ diameter from every batch and weight individually on electronic balance. The avg. weight was calculated.
Drug Content Uniformity: determined by dissolving the bio-flexy films $\left(1 \mathrm{~cm}^{2}\right.$ in diameter) in $100 \mathrm{ml}$ of phosphate buffer ( $\mathrm{pH}$ 7.4) for $24 \mathrm{hrs}$. Under occasional shaking. The $5 \mathrm{ml}$ solution was taken and diluted with phosphate buffer $\mathrm{pH} 7.4$ up to $20 \mathrm{ml}$, and the resulting solution was filtered through a $0.45 \mathrm{~mm}$ Whattman filter paper. The drug content was then determined after proper dilution using a UV spectrophotometer at $\lambda_{\max } 750 \mathrm{~nm}$.

Swelling Percentage Study: calculated by function of weight and area increase due to swelling. Bio-flexy films of size $\left(1 \times 1 \mathrm{~cm}^{2}\right)$ were weighed, kept in a petridish and $10 \mathrm{ml}$ distilled water was added. After one hour, the films were weighed. The difference in the weights gives the weight increase due to absorption of water and swelling of patch. The study was conducted for 24 hours.

$$
\% S=\left(X_{t}-X_{0} / X_{0}\right) \times 100
$$

where, $\mathrm{Xt}=$ weight or area of the swollen bio-flexy film after time $t$

$\mathrm{Xo}=$ original bio-flexy film weight or area at zero time

Percentage moisture uptake (PMU) was carried out to check the physical stability of the bio-flexy films at high humid conditions. Three $1 \mathrm{~cm}$ diameter bio-flexy films were cut out and weighed accurately then the films were placed in desiccator containing saturated solution of aluminium chloride, keeping the humidity inside the desiccator at $79.5 \%$. After 3 days the bio-flexy films were removed, weighed and percentage moisture absorption was calculated. Average percentage moisture absorption of three films was found.

Percentage moisture uptake $=[($ Final weight - Initial weight)/ Initial weight] X 100 


\section{Nanomedicine \& Nanotechnology Open Access}

In-Vitro Mucoadhesivity study of Isolated Biopolymer: The mucoadhesive property of Piper nigrum polymer was assessed by Modified Shear Stress Method at different concentrations $1 \%, 2 \%, 4 \%, 6 \%, 8 \%$ and $10 \%$ of biopolymer. The weight required to slide a glass plate by using various concentrations of the biomaterial solutions from 0-30 mins was determined and compared with Sodium Carboxyl Methyl Cellulose (Sodium CMC) (1\%).

Mucoadhesion study of formulated bio-flexy films by rotating cylinder method: In Rotating Cylinder method, the mucoadhesive property of bio-flexy films was evaluated by Capra aegagrus (goat) intestinal mucosa. Bio-flexy films of area $1 \mathrm{~cm}^{2}$ of each formulation were cut down using sharp blade. Tied the goat intestinal mucosa over the rotating basket of i-disso apparatus. The Dissolution medium was composed of $900 \mathrm{ml}$ buffer $\mathrm{pH}$ 7.4, maintained at $37^{\circ} \mathrm{C}$, subjected for rotation at $50 \mathrm{rpm}$. It was applied over the inner surface of goat intestinal mucosa until it got dislodged. The detachment and dislodgement of film from mucosal substrate was noted at regular intervals.

Mucoretention study of formulated bio-flexy films: Bio-flexy films of area $1 \mathrm{~cm}^{2}$ of each formulation were cut down using sharp blade. Tied the Capra aegagrus (goat) intestinal mucosa over slanting condenser over which buffer was allowed to flow from a burette. It was applied over the inner surface of goat intestinal mucosa until it got dislodged. The detachment and dislodgement of film from mucosal substrate was noted at regular intervals.

In-vitro drug release (by modified $M$.S. apparatus) $[9,10]$ : A thermostatically controlled compartment with vials containing buffer $\mathrm{pH} 7.4$ was prepared. Egg membranes tied to donor compartment (contained formulations) inserted into receiver compartment. Temperature was maintained at $37^{\circ} \mathrm{C}$ using orbital shaker incubator. Samples were withdrawn at regular intervals ranging from 10 mins to $30 \mathrm{hrs}$. Complete Replacement of buffer each time. Ultra Violet Spectral analysis was performed.

Stability studies: Stability studies were conducted as per ICH Guidelines. Stability testing of pharmaceutical product is done to ensure the efficacy, safety and quality of active drug substance and dosage forms and shelf life or expiration period. The stability studies of the formulations were conducted at $40^{\circ} \mathrm{C} \pm 2^{\circ} \mathrm{C}$ and $\pm 45 \pm 5 \%$ $\mathrm{RH}, 25 \pm 2^{\circ} \mathrm{C}$ and $60 \pm 5 \% \mathrm{RH}$ and $2 \pm 5^{\circ} \mathrm{C}$ temperature and $\mathrm{RH}$ values respectively. After every 15 days, the aggregation, nature, color change, and in-vitro drug release of formulations was determined $[11,12]$.

\section{Results and Discussion}

\section{Isolation of Biomaterial}

The biopolymer was isolated from pulp of Piper nigrum by simplified economic process. The optimization of biopolymer isolation process was repeated six times for and the \% yield was calculated. During optimization the results obtained were reproducible with insignificant variation and can be adopted for scaling up in bulk manner. The $\%$ yield for biomaterial from Piper nigrum was found to be $2.2 \% \pm 0.02$.

\section{Physicochemical Properties of Isolated Biomaterial}

It was tested positive i) for proteins and carbohydrates, amino acids were not present.

(i) Physical Properties: The biomaterial obtained from pulp of Piper nigrum was obtained in powdered texture that was dark brown in color, pungent odour, soluble in methanol. Its colour changing point was found to be $190^{\circ} \mathrm{C} \pm 1$.

\section{(ii) Chemical Properties}

(a) Test for Carbohydrates: Isolated biomaterial showed presence of Carbohydrates.

(b) Test for Protein: Isolated biomaterial showed presence of Protein.

(c) Test for Starch: Isolated biomaterial showed absence of Starch.

(d) Test for Reducing Sugar: Isolated biomaterial showed presence of Reducing Sugar.

\section{Drug Excipient Interaction Studies}

Drug-polymer interaction study of biomaterial isolated was done by UV techniques. The drug interaction study was performed by using wet and dry method.

a) Wet method $\lambda_{\max }$ was observed at $752 \mathrm{~nm}$, no significant difference than that of pure drug.

b) Dry method $\lambda_{\max }$ was observed at $752 \mathrm{~nm}$, no significant difference than that of pure drug.

Thus, no drug-excipient interaction occurred.

c) Colorimetry $0.05 \mathrm{gm}$. Topiramate showed color change with potassium permanganate from pink to 


\section{Nanomedicine \& Nanotechnology Open Access}

brown, indicating the reaction of potassium permanganate because of saturation of double bonds.

Drug (0.05 g) +bio-polymer (0.05 g) also showed a similar color change with potassium permanganate. This indicated that the drug was not entrapped. With the use of U.V. method $\lambda_{\max }$ of the drug-excipient mixture was found to be close to that of the pure drug. Thus, the drug-excipient interaction study revealed no interaction between the drug and the biomaterial and the biomaterial was found to be compatible with the drug. As no interaction was found, it can be concluded that the biomaterial may be useful in the formulation of Bio-Flexy films. Drug: Polymer 1:1 were mixed with Potassium Permanganate on glass plate. Observed color change, scrapped, Diluted suitably with distilled water, analyzed by UV. Similarly repeated with Drug: Distilled Water and Drug: Potassium Permanganate. Drug showed color change from pink to brown with Potassium Permanganate while polymer showed no color change. No significant difference in shift of $\lambda_{\max }$ than that of pure Topiramate was observed (Table 3).

\begin{tabular}{|c|c|c|c|c|c|c|c|}
\hline $\begin{array}{c}\text { Potassium } \\
\text { Permanganate }\end{array}$ & $\begin{array}{c}\text { Crystal } \\
\text { Violet }\end{array}$ & Iodine & $\begin{array}{c}\text { Copper } \\
\text { Sulphate }\end{array}$ & $\begin{array}{c}\text { Potassium } \\
\text { Dichromate }\end{array}$ & $\begin{array}{c}\text { Methyl } \\
\text { Red }\end{array}$ & $\begin{array}{c}\text { Methyl } \\
\text { Orange }\end{array}$ & Ferrous Sulphate \\
\hline Pink to brown color change & Purple & $\begin{array}{c}\text { Light } \\
\text { brown }\end{array}$ & Blue & $\begin{array}{c}\text { Light color } \\
\text { change }\end{array}$ & Red & Brown & Light brown \\
\hline
\end{tabular}

Table 3: Drug polymer interaction with different reagents.

\section{Spectral Studies of the Isolated Bio-Materials}

SEM Analysis It showed size range of biopolymer is
$100 \mu \mathrm{m}$. SEM showed flakes type fine structure with smooth texture (Figure 2).

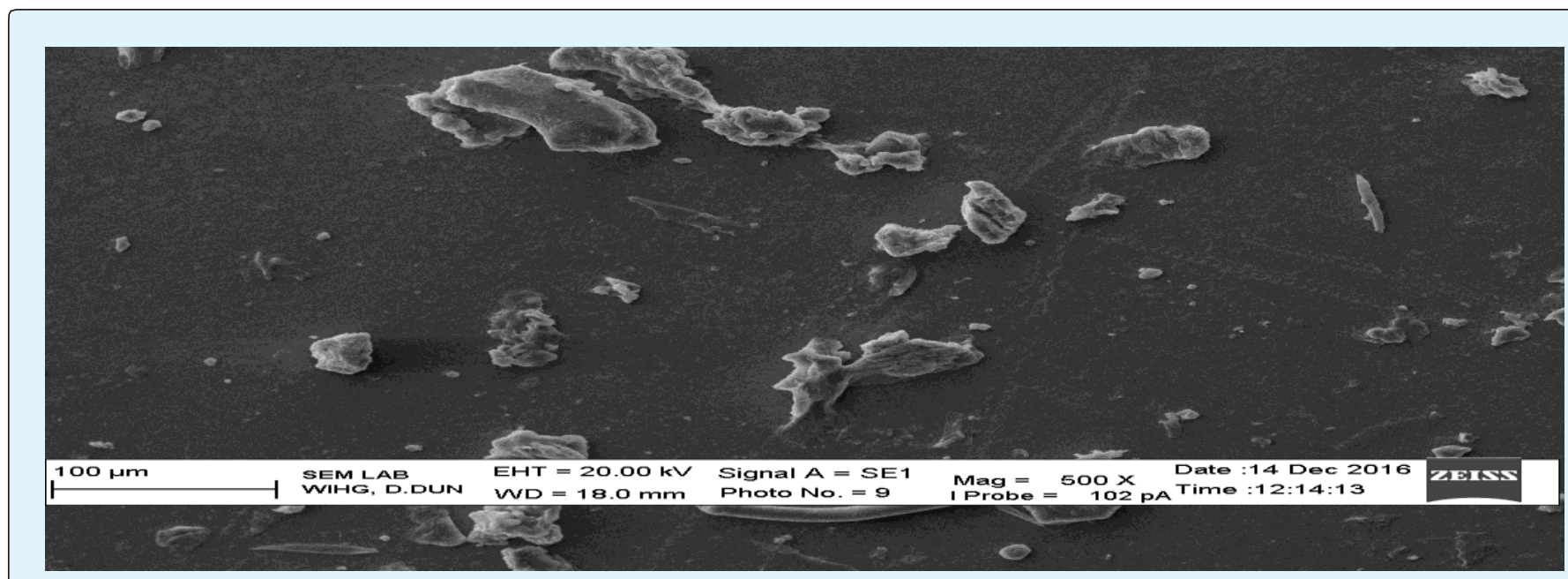

Figure 2: SEM of Piper nigrum biopolymer.

IR Spectroscopy (using IRPal2.0 software) The result of IR spectra of biomaterial isolated from Piper nigrum showed peaks at $3906 \mathrm{~cm}^{-1}, 3580 \mathrm{~cm}^{-1}, 1375 \mathrm{~cm}^{-1}$, $1309 \mathrm{~cm}^{-1}, 3377 \mathrm{~cm}^{-1}, 2361 \mathrm{~cm}^{-1}$ which clearly indicated inbuilt mucoadhesive property with functional groups $\mathrm{RCOOH}, \mathrm{RCH}_{2} \mathrm{OH}, \mathrm{RCONH}_{2}, \mathrm{~S}=\mathrm{O}, \mathrm{C}=\mathrm{C}-\mathrm{COOH}, \mathrm{RNH}_{2}$ (Figure 3). 


\section{Nanomedicine \& Nanotechnology Open Access}

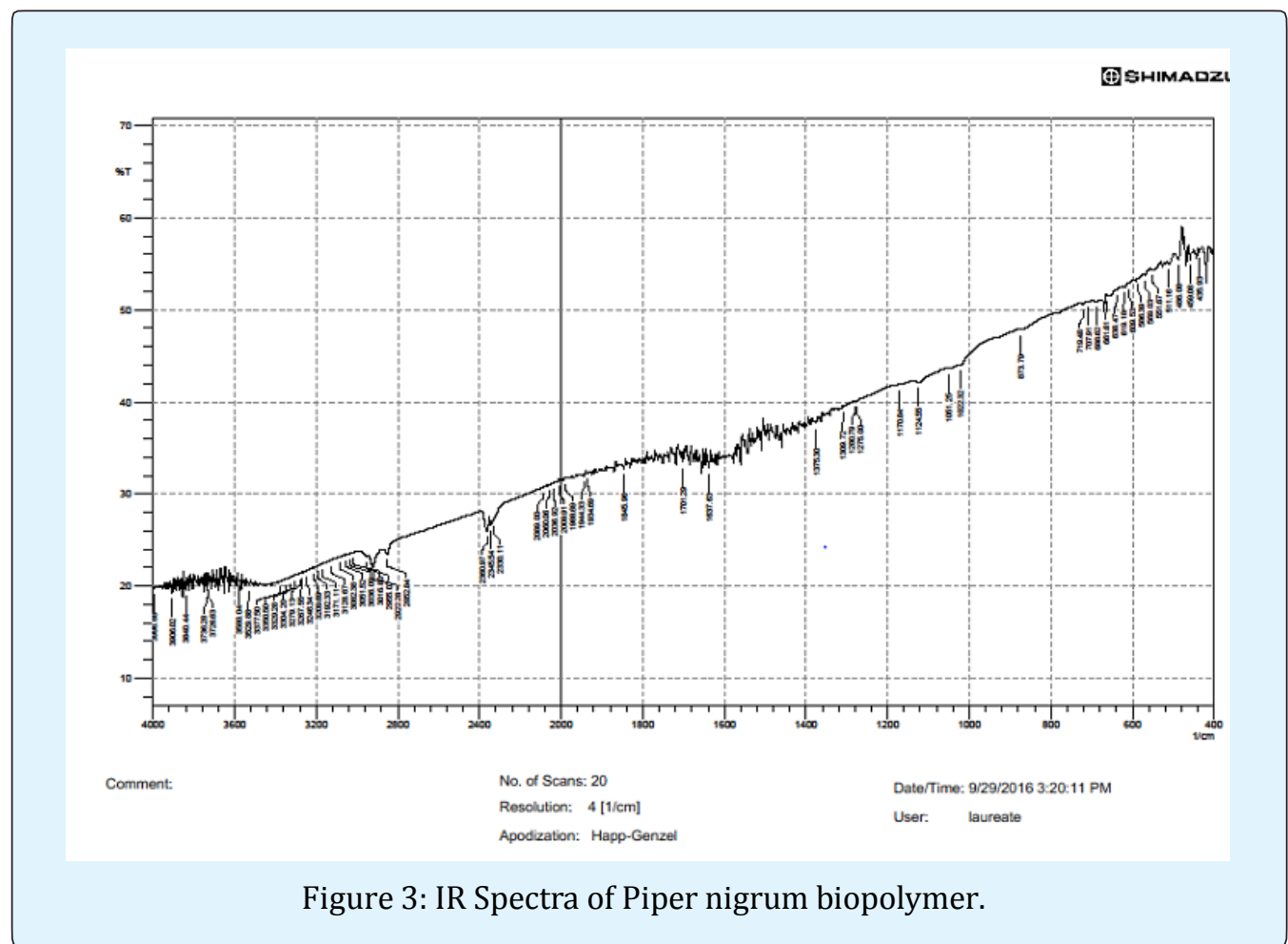

DSC: Peak was obtained at $78.42^{\circ} \mathrm{C}$, peak height is 0.8992 $\mathrm{mW}$, delta $\mathrm{H}$ is $45.9516 \mathrm{~J} / \mathrm{g}$, Onset depicts boiling point at

Polymer's Melting Temperature $\mathrm{T}_{\mathrm{m}}$ is $130^{\circ} \mathrm{C}$. Thus biopolymeric nature was confirmed (Figure 4). $45.11^{\circ} \mathrm{C}$, Glass Transition temperature is $106.90^{\circ} \mathrm{C}$.

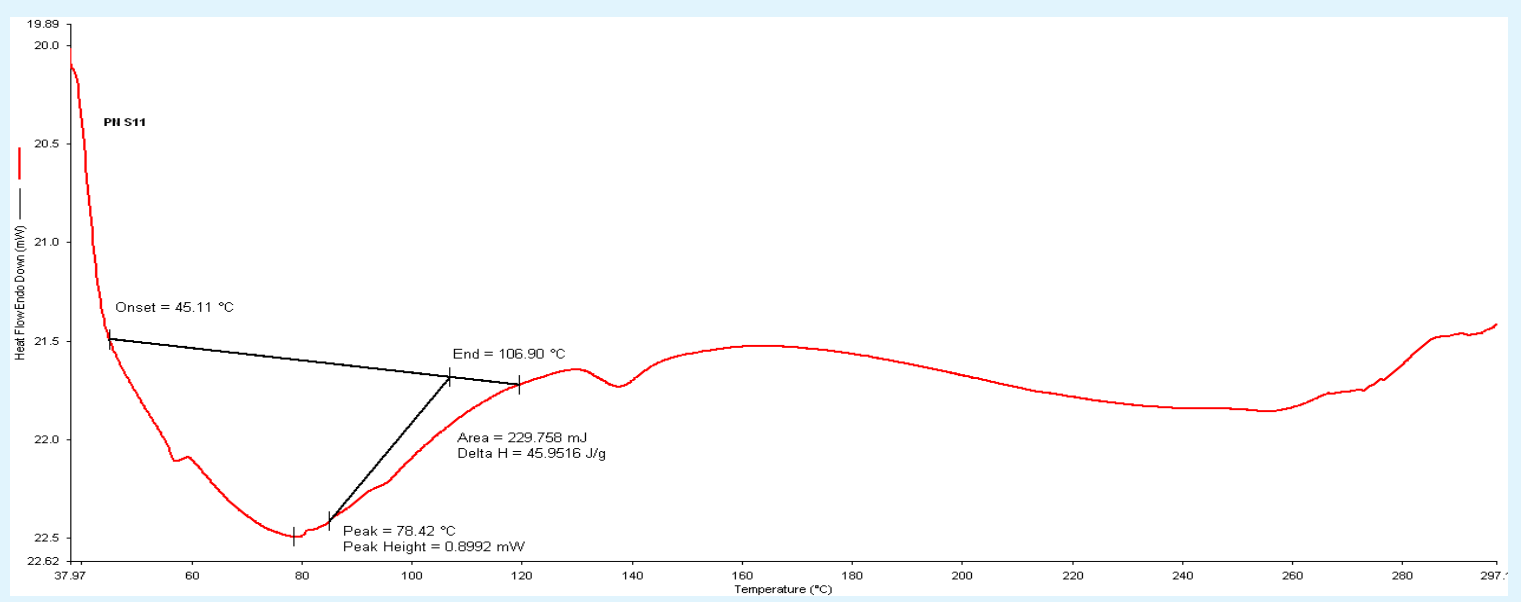

Figure 4: DSC Spectra of Piper nigrum biopolymer.

NMR Spectral Analysis: The presence of proton and their environment was confirmed by ${ }^{1} \mathrm{HNMR}$. The ${ }^{1} \mathrm{HNMR}$ Spectra confirms the presence of carbohydrates residue within the biopolymer extracted as the shift of carbohydrate ring protons are 3-6 ppm and the spectra when compared reflects the peak at $3.4191 \mathrm{ppm}$ (Figure 5). 


\section{Nanomedicine \& Nanotechnology Open Access}

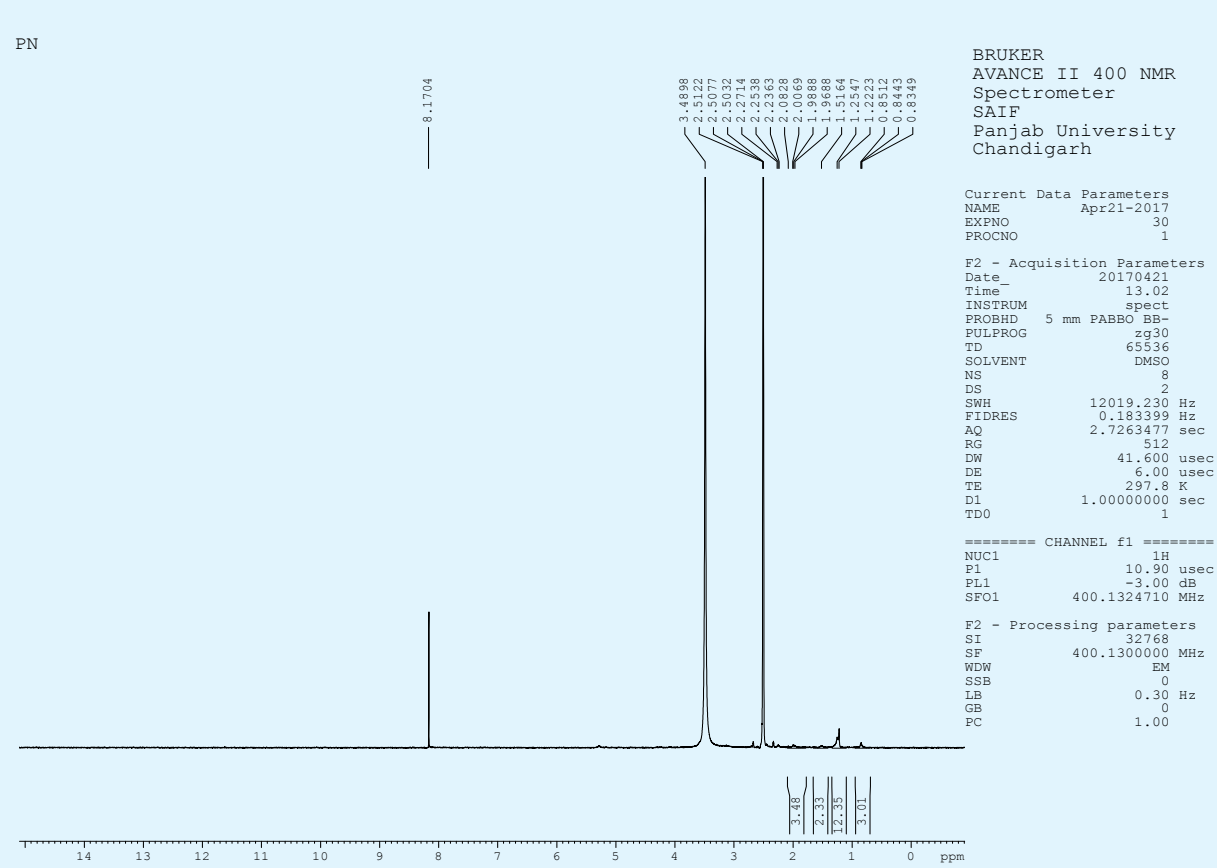

Figure 5: NMR Spectra of Piper nigrum biopolymer.

Preparation of Calibration Curve of Drug: Calibration

showed linearity. $\mathrm{R}^{2}$ value was found to be $\mathbf{0 . 9 9 4 5}$ curve of Topiramate was prepared in Buffer ( $\mathrm{pH}$ 7.4)

(Figure 6).

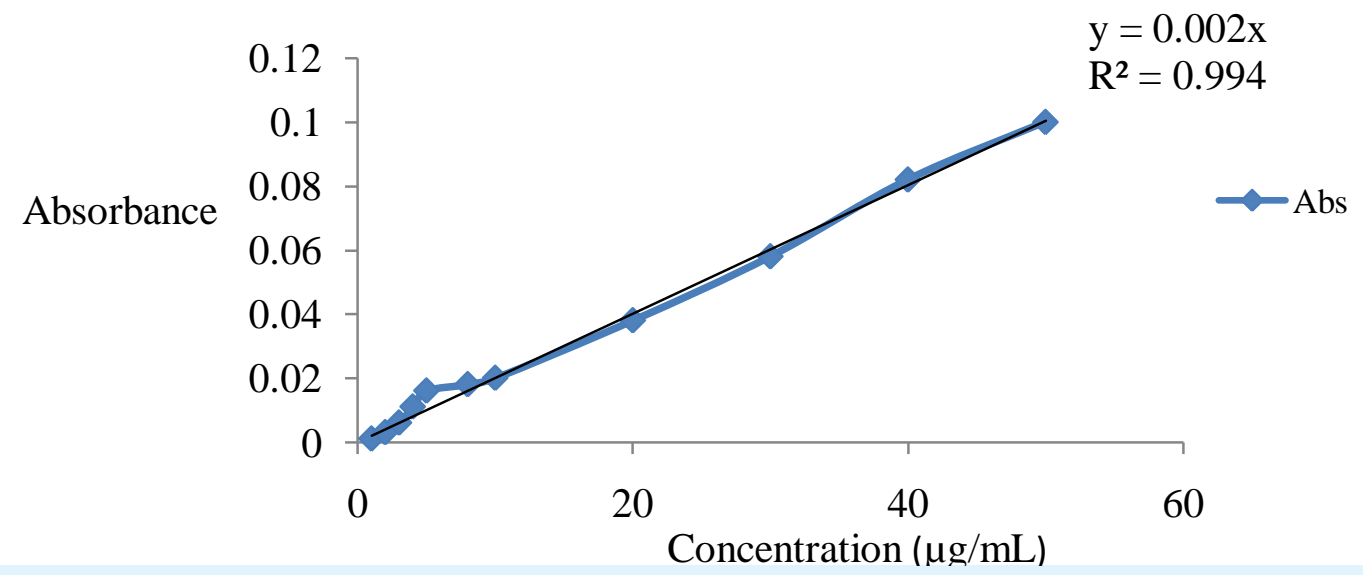

Figure 6: Standard curve of Topiramate in Buffer pH 7.4.

\section{Nanosizing of Topiramate}

The main purpose of Nanosizing Topiramate by two different methods was to compare novel method with published Standard Solvent Evaporation method which showed nanosized drug showed increase in \% Transmittance with increasing Wavelength in UV while 


\section{Nanomedicine \& Nanotechnology Open Access}

non-nanosized drug showed almost constant \% Transmittance (Figure 1).

\section{Evaluation Parameters of formulated Films}

Thickness of formulations: Thickness of nanosized Topiramate loaded bio-flexy films containing Piper nigrum biopolymer (FNO1-FNO5) was in range $0.027 \pm 0.006 \mathrm{~mm}$ to $0.037 \pm 0.002 \mathrm{~mm}$. As concentration of biopolymer was increased in formulations, thickness also increased although not much significant difference was found.

Folding endurance of formulations: The folding endurance was obtained in the range of 102-167 for nanosized Topiramate loaded Bio-flexy films containing Piper nigrum biopolymer (FN01-FNO5). As concentration of biopolymer was increased in formulations, folding endurance also increased as their flexibility got enhanced due to biopolymer.

Surface pH of formulations: Surface $\mathrm{pH}$ of nanosized Topiramate loaded bio-flexy films containing Piper nigrum biopolymer (FNO1-FNO5) was found to be $7.01 \pm 0.05$. Prepared formulations suitable for soft palatal delivery platform as they are in the range of physiological $\mathrm{pH}$.
Weight uniformity of formulations: Weight of nanosized Topiramate loaded bio-flexy films containing Piper nigrum biopolymer (FNO1-FNO5) was found to be in range of $0.020 \pm 0.05$ to $0.031 \pm 0.04$.

Drug content uniformity: Drug Content Uniformity of nanosized Topiramate loaded bio-flexy films containing Piper nigrum biopolymer (FNO1-FNO5) was found to be in range of $90.4 \% \pm 0.65$ to $98.6 \% \pm 0.60$. This indicates that drug was uniformly dispersed in bio-flexy films.

Swelling percentage study: Swelling Percentage Study of bio-flexy films containing Piper nigrum biopolymer (FN01-FNO5) ranged from $70 \% \pm 0.5$ to $73 \% \pm 0.3$. Swelling increased on increasing biopolymer content. It indicates that drug released through bio-flexy films by swelling followed by erosion.

Percentage Moisture Uptake (PTU) of bio-flexy films: Percentage Moisture Uptake (PTU) of bio-flexy films containing Piper nigrum biopolymer (FNO1-FNO5) was found to be in range of $2.2 \% \pm 0.13$ to $2.6 \% \pm 0.12$

Mucoadhesivity study of isolated biopolymer: Shear Stress study of Piper nigrum biopolymer revealed that $10 \%$ concentration showed promising mucoadhesivity comparable to standard Sodium Carboxyl Methyl (Sodium CMC) polymer (Table 4).

\begin{tabular}{|c|c|c|c|c|c|c|c|}
\hline \multirow{2}{*}{ Solutions } & \multicolumn{7}{|c|}{ TIME (mins) } \\
\cline { 2 - 8 } & $0 \mathrm{~min}$ & $5 \mathrm{mins}$ & $10 \mathrm{mins}$ & $15 \mathrm{mins}$ & $20 \mathrm{mins}$ & $25 \mathrm{mins}$ & $30 \mathrm{mins}$ \\
\hline Water & $6.3 \mathrm{gm}$ & $8.9 \mathrm{gm}$ & $10.3 \mathrm{gm}$ & $11.6 \mathrm{gm}$ & $13.9 \mathrm{gm}$ & $17.0 \mathrm{gm}$ & $22.7 \mathrm{gm}$ \\
\hline Biopolymer 1 \% & $8.7 \mathrm{gm}$ & $9.5 \mathrm{gm}$ & $10.9 \mathrm{gm}$ & $13.7 \mathrm{gm}$ & $17.8 \mathrm{gm}$ & $22.9 \mathrm{gm}$ & $28.2 \mathrm{gm}$ \\
\hline Biopolymer 2 \% & $14.3 \mathrm{gm}$ & $15.9 \mathrm{gm}$ & $19.7 \mathrm{gm}$ & $26.9 \mathrm{gm}$ & $29.6 \mathrm{gm}$ & $35.3 \mathrm{gm}$ & $38.6 \mathrm{gm}$ \\
\hline Biopolymer 4 \% & $15.9 \mathrm{gm}$ & $20.3 \mathrm{gm}$ & $26.3 \mathrm{gm}$ & $34.8 \mathrm{gm}$ & $38.5 \mathrm{gm}$ & $42.9 \mathrm{gm}$ & $50.2 \mathrm{gm}$ \\
\hline Biopolymer 6\% & $22.9 \mathrm{gm}$ & $26.5 \mathrm{gm}$ & $38.9 \mathrm{gm}$ & $45.9 \mathrm{gm}$ & $56.7 \mathrm{gm}$ & $58.8 \mathrm{gm}$ & $67.7 \mathrm{gm}$ \\
\hline Biopolymer 8\% & $35.6 \mathrm{gm}$ & $40.7 \mathrm{gm}$ & $48.9 \mathrm{gm}$ & $58.9 \mathrm{gm}$ & $67.2 \mathrm{gm}$ & $72.5 \mathrm{gm}$ & $88.9 \mathrm{gm}$ \\
\hline Biopolymer 10\% & $52.7 \mathrm{gm}$ & $55.9 \mathrm{gm}$ & $58.7 \mathrm{gm}$ & $65.8 \mathrm{gm}$ & $69.4 \mathrm{gm}$ & $74.1 \mathrm{gm}$ & $79.1 \mathrm{gm}$ \\
\hline Sodium CMC 1\% & $49.1 \mathrm{gm}$ & $52.5 \mathrm{gm}$ & $59.5 \mathrm{gm}$ & $75.3 \mathrm{gm}$ & $98.6 \mathrm{gm}$ & $116 \mathrm{gm}$ & $129.2 \mathrm{gm}$ \\
\hline
\end{tabular}

Table 4: Mucoadhesivity of Piper nigrum biopolymer.

Mucoadhesion Study of Formulated nanosized method (Table 5). Topiramate loaded Bio-flexy Films by Rotating Cylinder 


\section{Nanomedicine \& Nanotechnology Open Access}

Dynamic Method

\begin{tabular}{|c|c|c|c|c|}
\hline S.No. & Formulation & Dislodgement Time (mins) & Formulation & Dislodgement Time (mins) \\
\hline 1 & FNO1 (1:1) & 60 & FSO1 (1:1) & 15 \\
\hline 2 & FNO2 (1:3) & 90 & FSO2 (1:3) & 20 \\
\hline 3 & FNO3 (1:5) & 120 & FSO3 (1:5) & 30 \\
\hline 4 & FNO4 (1:6) & 180 & FSO4 (1:6) & 45 \\
\hline 5 & FNO5 (1:10) & 210 & FSO5 $(1: 10)$ & 60 \\
\hline
\end{tabular}

Table 5: Dynamic Method.

Mucoretention study of formulated nanosized topiramate loaded bio-flexy films: Mucoretentive Study by Dynamic and Static Methods revealed that Nanosized
Topiramate loaded bio-flexy films containing Piper nigrum are mucoretentive on Capra aegagrus intestinal mucosa for considerable time period (Table 6).

\section{Static Method}

\begin{tabular}{|c|c|c|c|c|}
\hline S.No. & Formulation & Dislodgement Time (mins) & Formulation & Dislodgement Time (mins) \\
\hline 1 & FNO1 $(1: 1)$ & 90 & FSO1 $(1: 1)$ & 30 \\
\hline 2 & FNO2 $(1: 3)$ & 120 & FSO2 $(1: 3)$ & 60 \\
\hline 3 & FNO3 $(1: 5)$ & 180 & FSO3 $(1: 5)$ & 90 \\
\hline 4 & FNO4 $(1: 6)$ & 210 & FSO4 $(1: 6)$ & 120 \\
\hline 5 & FNO5 $(1: 10)$ & 240 & FSO5 $(1: 10)$ & 150 \\
\hline
\end{tabular}

Table 6: Static Method.

In-vitro release study by modified M.S. apparatus: Best Formulation was found to be FNO1 (Bio-Flexy film containing Topiramate: Piper nigrum biopolymer in ratio of 1:1) as shown in Figure 7 (comparative graph of
In-Vitro Drug Release of Formulations FNO1 to FNO5 by Modified M.S. Apparatus) and Figure 8 (comparative graph of In-Vitro Drug Release of Formulations FSO1 to FSO5 by Modified M.S. Apparatus) (Tables 7-10).

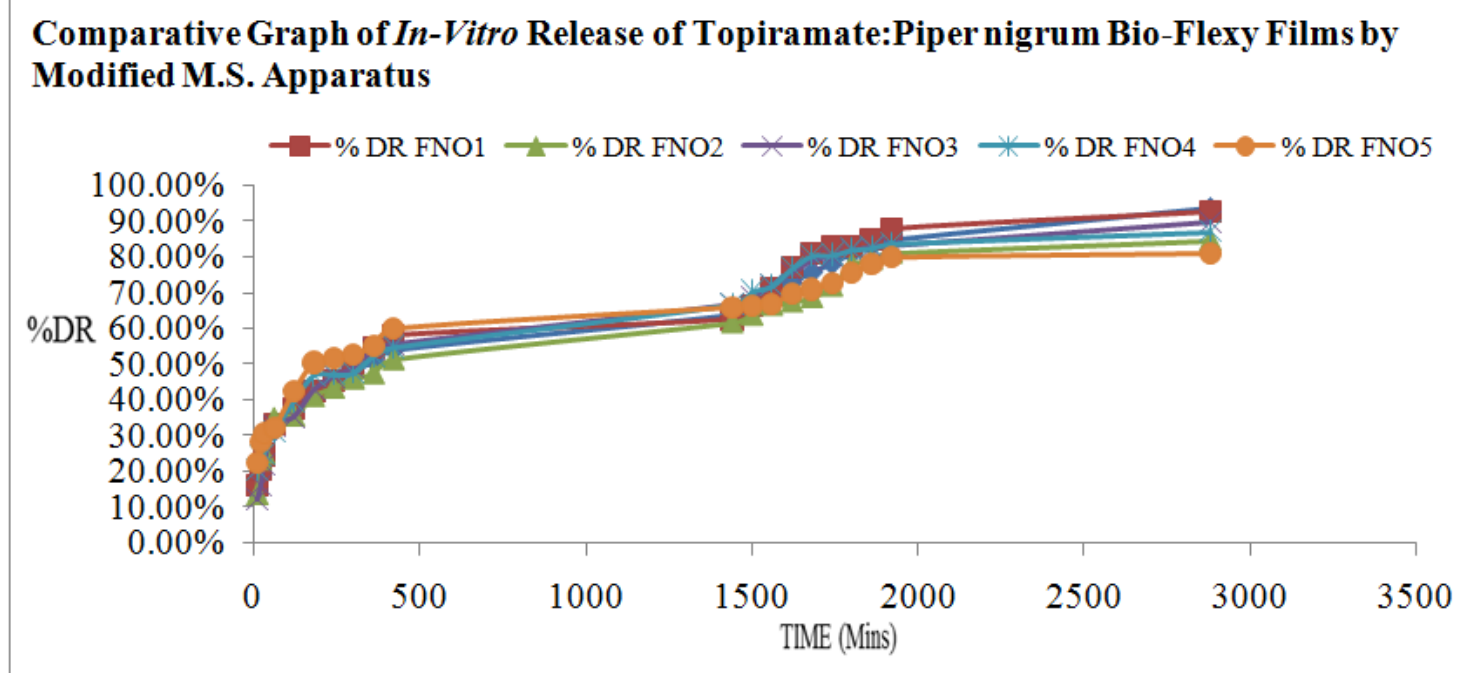

Figure 7: In-Vitro drug release of Topiramate bio-flexy films using Solanum melongena biopolymer by Modified M.S. apparatus (Dynamic Method) (FNO1-FNO5). 


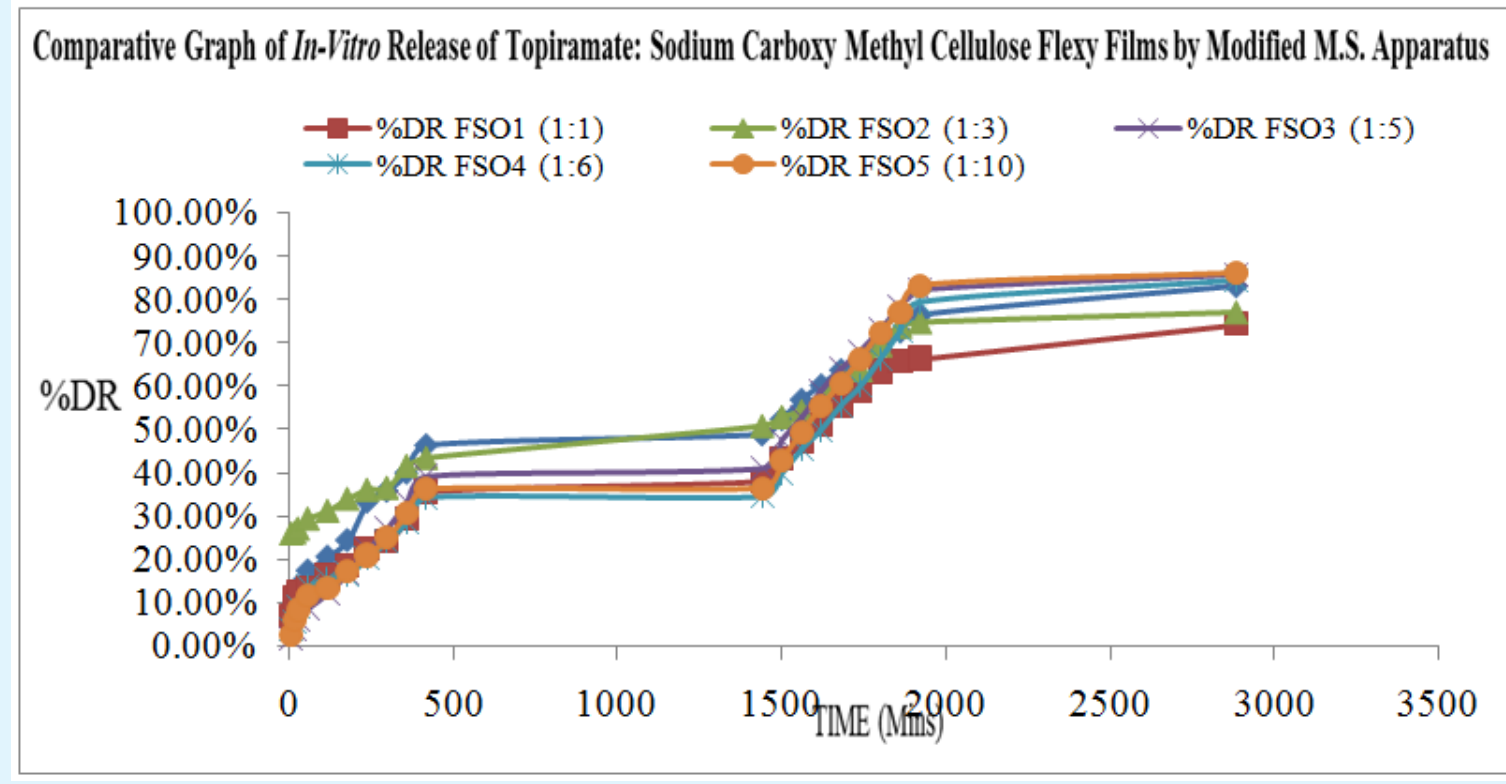

Figure 8: In-vitro drug release of Topiramate bio-flexy films using Sodium Carboxyl Methyl Cellulose (Sodium CMC) by Modified M.S. apparatus (Dynamic Method) (FSO1-FSO5).

\begin{tabular}{|c|c|c|}
\hline Ratio & T50 \% (hrs.) & T80 \% (hrs.) \\
\hline FNO1 (1:1) & 5 hrs. & 28 hrs. \\
\hline FNO2 (1:3) & 7 hrs. & 31 hrs. \\
\hline FNO3 (1:5) & 5 hrs. & 29 hrs. \\
\hline FN04 (1:6) & $\mathbf{6}$ hrs. & $\mathbf{2 8}$ hrs. \\
\hline FNO5 (1:10) & 3 hrs. & 32 hrs. \\
\hline
\end{tabular}

Table 7: T50\% and T80\% values of Topiramate-Piper nigrum polymer bio-flexy Films.

\begin{tabular}{|c|c|c|}
\hline Ratio & T50 \% (hrs.) & T80 \% (hrs.) \\
\hline FS01(1:1) & $\mathbf{2 7 ~ h r s . ~}$ & $\mathbf{4 8 ~ h r s . ~}$ \\
\hline FSO2(1:3) & $24 \mathrm{hrs}$. & $48 \mathrm{hrs}$. \\
\hline FSO3(1:5) & $26 \mathrm{hrs}$. & $31 \mathrm{hrs}$. \\
\hline FSO4(1:6) & $27 \mathrm{hrs}$. & $32 \mathrm{hrs}$. \\
\hline FSO5(1:10) & $26 \mathrm{hrs}$. & $31 \mathrm{hrs}$. \\
\hline
\end{tabular}

Table 8: T50\% and T80\% values of Topiramate-Sodium Carboxyl Methyl Cellulose Flexy Films.

\begin{tabular}{|c|c|c|c|c|c|c|c|}
\hline \multicolumn{8}{|c|}{ Release Kinetics Analysis Dynamic Method Formulation of Topiramate: Piper nigrum Bio-Flexy Films } \\
\hline \multirow[b]{2}{*}{ Formulations } & \multicolumn{5}{|c|}{$\mathbf{R}^{2}$} & \multirow[b]{2}{*}{ Best Fit Model } & \multirow[b]{2}{*}{ Mechanism of Action } \\
\hline & $\begin{array}{c}\text { Zero } \\
\text { order }\end{array}$ & $1^{\text {st }}$ order & $\begin{array}{l}\text { Higuchi } \\
\text { Matrix }\end{array}$ & Peppas & $\begin{array}{l}\text { Hixon } \\
\text { Crowell }\end{array}$ & & \\
\hline FNO1 (1:1) & 0.8251 & 0.8259 & 0.9185 & 0.9776 & 0.8256 & Peppas Korsmeyer & Fickian Diffusion (Higuchi Matrix) \\
\hline FNO2 (1:3) & 0.8258 & 0.8266 & 0.9146 & 0.9643 & 0.8264 & Peppas Korsmeyer & Fickian Diffusion (Higuchi Matrix) \\
\hline FNO3 (1:5) & 0.8198 & 0.8206 & 0.9272 & 0.9689 & 0.8204 & Peppas K & Fickian Diffusion (Higu \\
\hline FNO4 (1:6) & 0.8218 & 0.8226 & 0.9146 & 0.9892 & 0.8224 & Peppas Korsmeyer & Fickian Diffusion (Higuchi Matrix) \\
\hline FNO5 (1:10) & 0.728 & 0.7289 & 0.9117 & 0.9736 & 0.7286 & Peppas Korsmeyer & Fickian ion(Higuchi Matrix) \\
\hline
\end{tabular}

Table 9: Kinetic release of Topiramate-Piper nigrum polymer bio-flexy films. 


\section{Nanomedicine \& Nanotechnology Open Access}

Kinetic Release of Topiramate-Sodium Carboxyl Methyl Cellulose (Sodium CMC) flexy films

\begin{tabular}{|c|c|c|c|c|c|c|c|}
\hline \multicolumn{8}{|c|}{$\begin{array}{l}\text { Release Kinetics Analysis Dynamic Method Formulations of Topiramate: Sodium Carboxyl Methyl Cellulose } \\
\text { Flexy Films }\end{array}$} \\
\hline \multirow{3}{*}{ Formulations } & \multicolumn{5}{|c|}{$\mathbf{R}^{2}$} & \multirow{3}{*}{ Best Fit Model } & \multirow{3}{*}{ Mechanism of Action } \\
\hline & \multirow{2}{*}{\begin{tabular}{|c|} 
Zero \\
order \\
\end{tabular}} & \multirow{2}{*}{$1^{\text {st }}$ order } & \multirow{2}{*}{ Higuchi Matrix } & \multirow{2}{*}{ Peppas } & \multirow{2}{*}{$\begin{array}{c}\text { Hixon } \\
\text { Crowell }\end{array}$} & & \\
\hline & & & & & & & \\
\hline FSO1 (1:1) & 0.917 & 0.9172 & 0.9311 & 0.961 & 0.9171 & Peppas Korsmeyer & $\begin{array}{l}\text { Fickian Diffusion (Higuchi } \\
\text { Matrix) }\end{array}$ \\
\hline FSO2 (1:3) & 0.8454 & 0.846 & 0.8947 & 0.9009 & 0.8458 & Peppas Korsmeyer & $\begin{array}{l}\text { Fickian Diffusion (Higuchi } \\
\text { Matrix) }\end{array}$ \\
\hline FSO3 & 05 & $\mathbf{0}$. & & 0.9 & 0.9051 & $\mathbf{P e}$ & Anomalous \\
\hline FSO4 (1:6) & 0.8963 & 0.8963 & 0.9319 & 0.9566 & 0.8963 & Peppas Kor & $\begin{array}{l}\text { Fickian Diffusion (Higuchi } \\
\text { Matrix) }\end{array}$ \\
\hline FSO5 (1:10) & 0.8989 & 0.8989 & 0.9371 & 0.9614 & 0.8989 & Peppas Korsmeyer & Anomalous Transport \\
\hline
\end{tabular}

Table 10: Kinetic Release of Topiramate-Sodium Carboxyl Methyl Cellulose (Sodium CMC) flexy films.

Stability studies: The formulations showed no physical changes, related to the color, odor, taste etc. The drug content and in-vitro release was found to be the same, no significant change was observed. So it was concluded that the formulation bio-flexy films of Topiramate was found to be stable.

\section{Discussion}

The rationale of research work was to explore a novelistic route for brain specifically via Trans Soft Palatal route. The potential of nanosized Topiramate loaded bioflexy films for Trans-Soft palatal to brain drug delivery was investigated. Biopolymer was isolated from natural edible sources of Piper nigrum pulp. Biopolymers was used to prepare flexy films because of its biodegradability, biocompatibility, non-toxic, non- irritant nature and no reaction on soft palatal surface. Drug polymer interaction was not observed because no change in wavelength of pure drug and drug to polymer ratio. Biopolymer was devoid of irritancy to soft palate because of their inertness, so biopolymers were selected for formulating nanosized topiramate loaded bio-flexy films. Biopolymers showed excellent film forming properties along with mucoadhesive and mucoretentive properties. Bio-Flexy films were prepared by easiest, economic and reproducible solvent casting technique. Bio-Flexy films formulations provided sustained drug action up to 48 hours. A smart conclusion was drawn that the isolated biopolymer possessed in-built filmability and mucoadhesive properties and served as bio-excipients for formulating nanosized drugs loaded bio-flexy films. Soft palatal drug delivery bypasses oral route and reduces economic and API dose burden in patients. As bio-flexy films were prepared using biopolymer, it is more economic and safer than synthetic polymers used in marketed formulations. Bio-flexy films are easy to administer and remove/ discontinue from site of administration. Soft palate is non-keratinized, devoid of salivary enzymes so minimal drug wastage occurs. Bioflexy films were prepared by solvent casting technique which is the easiest and reproducible method to prepare flexy film without need of any sophisticated instruments. Drug to polymer ratio was chosen at five levels for Piper nigrum; FNO1 (1:1), FNO2 (1:3), FNO3 (1:5), FNO4 (1:6), FNO5 (1:10), and five levels for Sodium carboxyl methyl cellulose FSO1 (1:1), FSO2 (1:3), FSO3 (1:5), FSO4 (1:6), FSO5 (1:10). Prepared bio-flexy films of $1 \mathrm{~cm}^{2}$ were cut using a round punch for evaluation parameters and stability studies. The percentage yield of Solapur melongen a biopolymer was found to be $0.58 \% \pm 0.02$. Shear Stress study of Piper nigrum biopolymer revealed that $10 \%$ concentration showed promising mucoadhesivity comparable to standard Sodium Carboxyl Methyl (Sodium CMC) polymer. Thickness of nanosized Topiramate loaded bio-flexy films containing Piper nigrum biopolymer (FMO1-FMO5) was ranging from $0.027 \pm 0.006 \mathrm{~mm}$ to $0.037 \pm 0.002 \mathrm{~mm}$, Folding Endurance: 102-167, Surface pH: $7.01 \pm 0.05$ to $7.01 \pm 0.03$, Weight Uniformity: $0.020 \pm 0.05$ to $0.031 \pm 0.04$, Drug Content Uniformity: $\quad 90.4 \% \pm 0.65$ to $98.6 \% \pm 0.60$, Swelling Percentage: $70 \% \pm 0.5$ to $73 \% \pm 0.3$, Tensile Strength: 89.38 gm \pm 2.8 to 100.05 gm \pm 2.4 , Percentage Moisture Uptake (PTU): $2.2 \% \pm 0.13$ to $2.6 \% \pm 0.12$, more mucoretentive on Capra aegagrus intestinal mucosa than standard Sodium Carboxyl Methyl Cellulose films. 


\section{Nanomedicine \& Nanotechnology Open Access}

Based on all above mentioned evaluation parameters, FNO4 (containing Topiramate: Piper nigrum biopolymer (1:6)) flexy film having $\mathbf{R}^{2}=\mathbf{0 . 9 8 9 2}$, Peppas Korsemeyer as best fit model, follows Fick an Diffusion (Higuchi Matrix) release mechanism, T50\%: 6 hrs., T80\%: 28 hrs. using BITS Software 1.12.Stability study revealed stable bio-flexy films with no significant change in physical appearance and stable $\mathrm{pH}$. Prepared formulations of Topiramate loaded bio-flexy films containing Piper nigrum biopolymer were suitable for Soft Palatal Delivery.

\section{Conclusion}

In this research work, nanosized Topiramate loaded bio-flexy films (containing Piper nigrum isolated biopolymer) were formulated and evaluated in comparison to standard Sodium Carboxyl Methyl Cellulose polymer containing Films of Topiramate. The study aims to determine suitability of isolated biopolymer as bio-excipient in formulating nanosized drug loaded bio-flexy films to be delivered by Soft Palatal route for Epilepsy treatment. The results of all evaluation parameters revealed that controlled drug release can be achieved by this drug delivery route up to $48 \mathrm{hrs}$. Formulation FNO4 (containing Topiramate: Piper nigrum biopolymer (1:6)) was selected as Best Film and was also suitable for Soft Palatal route. This study can be used as an alternative economic and safe therapy for treatment of Epilepsy in low dose. (as drug is nanosized so lesser amount of drug is used than normal oral dose).

\section{Acknowledgement}

We wish to acknowledge Prof. K.K. Raina (Vice Chancellor, DIT University) and Mr. Anuj Aggarwal, (Chairman, DIT University) for providing the platform for research.

\section{References}

1. http://en.wikipedia.org/wiki/soft

2. http://en.wikipedia.org/wiki/nerve

3. Shakya P, Madhav NVS, Shakya AK (2011) Palatal mucosa as a route for Systemic Drug Delivery: a Review. J Controlled Release 151(1): 2-9.
4. Ahmad N (2012) Biological role of Piper nigrum L. (Black pepper): A review Asian Pacific Journal of Tropical Biomedicine 2(3): 945-953.

5. Nilani P (2010) Formulation and Evaluation of Polysaccharide Based Biopolymer - an Ecofriendly Alternative for Synthetic Polymer. J Pharm Sci Res 2(3): 178-184.

6. Madhav NVS, Pangatey A (2015) has filed an Indian Patent. Development of Flexy Bioadhesive Film loaded with Nanosized Zidovudine for brain specificity via novelistic Soft Palatal route.

7. Hearnden V, Hull K, Juras DV, Greenberg M, Kerr AR, et al. (2012) New developments and Opportunities in Oral Mucosal Drug Delivery for local and systemic disease. Adv Drug Deliv Rev 64(1): 16-28.

8. Patil S, Asema SUK, Mirza S, Ahmed Zaheer, Maqdoom Farooqui (2008) Method Development and Validation for Quantitative Analysis of TIGABINE HCL by Ultraviolet Spectrophotometry. Int J Chem Sci 6(1): 413-416.

9. Madhav NVS, Tangri P (2012) Design and Evaluation of Insulin loaded Bio-films for Trans-Soft Palatal to Brain Delivery. Int J Therapeutic Applications 4: 1018.

10. Madhav NVS, Shakya AK, Singh K, Shakya P (2011) Histological and Mucoadhesion Studies on Transpalatal Mucoadhesive disks of Rosiglitazone Maleate. International Journal of Drug Delivery 3(3): 456-466.

11. Madhav NVS, Shakya A, Shakya P, Singh K (2009) OroTransmucosal Drug Delivery Systems: A Review. J Controlled Release 140(1): 2-11.

12. Madhav NVS, Tangri P (2011) Oral Mucoadhesive Drug Delivery Systems: A Review. Int J Biopharmaceutics 2(1): 36-46.

13. Madhav NVS, Uma Shankar US, Emdad HE (2006) Soft Palate-A Novel Platform for Transmucosal Delivery of Amikacin. Proceedings of International Conference on Ethnopharmacology and Alternative Medicine, held at Amla Cancer Institute, Trissur.
Varshney S and Satheesh Madhav NV. Smart Approach for Preparing Nanosized
Topiramate Loaded Bio-Flexy Films Using Film Former from Piper Nigrum and
Screening its In-Vitro Performance. Nanomed Nanotechnol 2018, 3(3): 000147.
Copyright(C) Varshney S and Satheesh Madhav NV. 